\title{
Impact of COVID-19 awareness on health-related behavior among adolescents in Nepal
}

\author{
Bidhya Banstola $^{1 *}$ (D), Durga Dhungana ${ }^{2}$ (D) \\ 'Nursing Programme, Manipal College of Medical Sciences, Pokhara, Nepal, \\ ${ }^{2}$ Department of Internal Medicine, Gandaki Medical College Teaching Hospital and Research Center, Pokhara, Nepal.
}

\begin{abstract}
Introduction: With occurrence of COVID-19, many countries have initiated lockdown in an effort to control the pandemic. These measures can only be effective when the people co-operate. The awareness and health-related behavior have a major role in determining society's response. Meanwhile adolescents are at the risk of deviating from disciplined health-related behaviors due to turbulence arising from their hormones despite of their awareness. This study aims to study COVID-19 awareness and its impact on health-related behavior of adolescents. Methods: A descriptive cross-sectional web-based online study of 299 adolescents enrolled in various educational programs, between ages 13 to 19 years was conducted between June 18, 2020 and July 11, 2020 in Nepal. The questionnaire consisted of demographic characteristics, 16 items on knowledge and 40 items on behavior. Descriptive statistics, chi-square tests and binary logistic regression were conducted in Statistical Package for the Social Sciences. Results: A total of 299 adolescents were enrolled in the study. Majority (92.6\%) of the adolescents had adequate awareness. Positive health-related behavior was seen in $72 \%$ of the adolescents. Spiritual behavior was the most affected in comparison to physical, social and psychological behavior. Adolescents with adequate awareness on COVID-19 were 10.67 times more likely to perform positive health related behavior ( $\mathrm{P}=0.005 ; 95 \% \mathrm{CI}=2.01-56.47)$. Conclusion: Majority of the adolescents had adequate awareness. Significant percentage of adolescents had positive health-related behavior. Positive behaviour was not proportionately in level with adequate awareness. Effective health programs and policies are needed to transform adequate awareness into positive health-related behaviour for effective control of disease.
\end{abstract}

Keywords: adolescents, awareness, COVID-19, health-related behaviours, impact.

\section{*Correspondence:}

Bidhya Banstola, BN, MN (Paediatrics)

Lecturer, Nursing Programme, Manipal College

of Medical Sciences, Pokhara, Nepal

Email:bidhya77@gmail.com

Submitted: February 22, 2021

Accepted: June 14, 2021

To cite: Banstola $B$, Dhungana $D$, Impact of COVID-19 awareness on health-related behaviour among adolescents in Nepal. JGMC Nepal. 2021;14(1):54-8.

DOI: $10.3126 /$ jgmcn.v14i1.35124

\section{INTRODUCTION}

Corona Virus Disease has been emerging in the world originating from Wuhan, Hubei Province of China reporting a cluster of cases of pneumonia on $31^{\text {st }}$ of December 2019. The disease then turned to be pandemic outbreak with droplet transmission throughout the world. A severe respiratory disease was initially managed in the line of Severe Acute Respiratory Syndrome (SARS) and Middle East Respiratory Syndrome (MERS) like disease and eventually isolated to be Novel Corona Virus in laboratory testing. The disease being transmitted from human to human with increasing number outside the china forced the World Health Organization to announce COVID 19 as a Public Health Emergency of International Concern. ${ }^{1}$

Adolescents' knowledge may affect health-related behavior which can either enhance or further worsen the state of being healthy. Adolescents are not indifferent to the impact of the pandemic. Understanding their reactions and emotions is essential to properly address their needs. ${ }^{2}$ Adolescents may be more likely to engage in behaviors that contribute to the spread of the infection. ${ }^{3}$ To guarantee the final success, people's adherence to these control measures are 
essential, which is largely affected by their knowledge and behaviors towards COVID-19 in accordance with Knowledge Attitude and Practice theory. ${ }^{4}$

Research related to this field has been nominal in Nepal to the knowledge of the researcher. Hence this study aims to assess awareness regarding COVID-19, health behavior and impact of awareness on health related behavior among adolescents.

\section{METHODS}

This was a descriptive cross sectional web-based online study done in Nepal from June 18, 2020 to July 11, 2020. The ethical clearance for conducting the study was taken from the Institutional review committee of Manipal Teaching Hospital (Ref: MEMG/IRC/347/GA). Adolescents enrolled in educational programs, between ages of 13 to 19 years and with internet services were included in this study.

A structured self-administered questionnaire was developed and used as main research instrument. The self-administered questionnaire consisted of sociodemographic questions, 16 questions related to awareness about COVID-19 and 40 items related to health-related behavior. Questions of awareness were prepared based on international guidelines and research instrument used in other studies. ${ }^{5,6}$ It included 16 multiple-choice questions followed by the calculation of a total cumulative knowledge score for each participant. One point was given for each question if answered correctly. Questions having multiple responses as correct answers had equally divided score out of one. Awareness was categorized with adolescents scoring less than 8 and more than 8 as having "Adequate" and "Inadequate" respectively. Health related behavior was assessed on physical, social, psychological and spiritual domain. Each item consisted of 5 point likert scale ranging from 1 to 5 representing not at all, once or twice, a few times, often and very often respectively. The summed score of at least $60 \%$ in each domain and as total was categorized as positive behavior for each domain and as total respectively. Pretesting of tool was done among 30 adolescents before conducting the study. Internal consistency of the health-related behavior items were assessed by Cronbach's alpha coefficient and found to be $0.76 .^{7}$

The sample size was estimated using Cochran's formula on an assumption that the level of awareness and its impact on their health related behavior as a prevalence of $50 \%$ since no such studies being done yet regarding the impact of knowledge on health related behaviour of adolescents. ${ }^{8,9}$

Taking $95 \% \mathrm{CI}$ and 6\% margin of error then sample size was calculated by using formula,

$\mathrm{n}=\mathrm{Z}^{2} \times \mathrm{p} \times \mathrm{q} / \mathrm{e}^{2}$

$=(1.96)^{2} \times(0.5) \times(1-0.5) /(0.06)^{2}$

$=267$

By taking $10 \%$ non-response error the actual sample size of this research was 294.

Adolescents as primary respondents were identified with the link of researcher from different provinces of Nepal. Furthermore, snowball sampling was used to get access to other respondents via the primary respondents. Messenger along with Google mail was used as an application to send the link of online questionnaire to adolescents from the portal of Google form. Assent of adolescents were taken from the form attached in Google form and informed consent from parents were taken via phone call. The contact number of the parents was asked from adolescents during the time of assent.

Statistical Package for the Social Sciences (SPSS) software 21 was used to analyze the data retrieved from Google form. Descriptive statistical methods were used to summarize data on socio-demographic characteristics as frequencies and percentage. Chi-square continuity correction was used to assess the association of awareness and healthrelated behaviors with socio-demographic characteristics. Furthermore, to ascertain the impact of awareness on health-related behavior binary logistic regression was used.

\section{RESULTS}

Out of 340 responses of online based web survey, 299 responses were found as per the inclusion criteria and were included in the study. Majority of the adolescents (72.9\%) were in age group 17 and above with median age of $17 \pm 1.713$ years. Approximately two-thirds (65.9\%) of the adolescents were from Gandaki Province. A quarter of the adolescents had frontline worker in their family. (Table 1)

Adequacy of awareness on COVID-19 significantly differed across stream of education, education levels of parents and annual family income $(\mathrm{P}<0.05)$. Adolescents studying above Class 10 were found likely to have adequate awareness but not statistically significant. Adolescents with frontline health worker in family were found to have inadequate awareness though statistically insignificant $(\mathrm{P}=0.25)$ (Table 1) 
Table 1. Socio-demographic factors associated with adequate awareness.

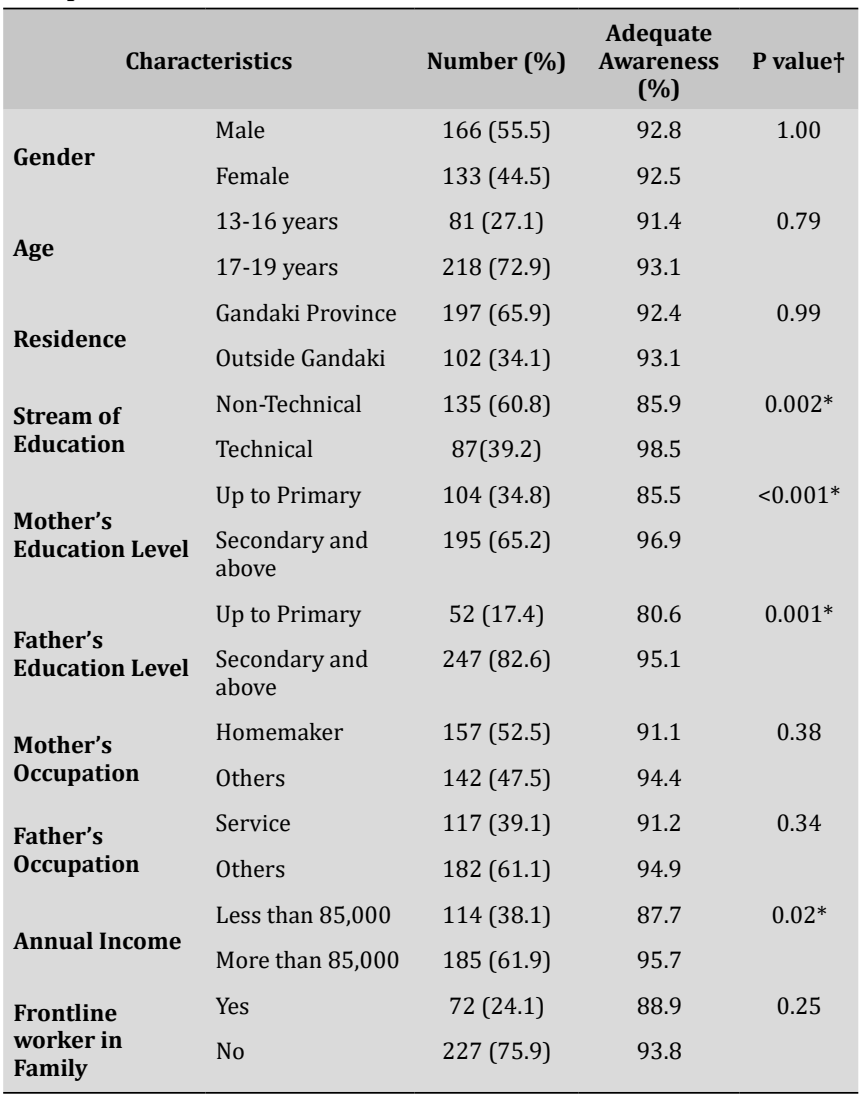

${ }^{*} \mathrm{P}$ value significant $\leq 0.05+$ Chi-square continuity correction

Among the various behavior domains, more had positive psychological behavior followed by social and physical domain. Only about one-fifth of adolescents had positive spiritual behavior. (Figure 1)

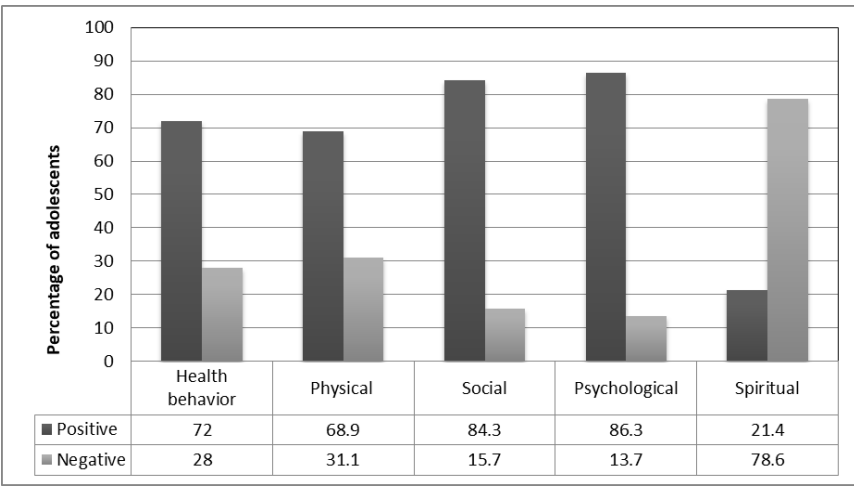

Figure 1. Heath-related behaviors across four domains

Positive behavior were significantly found to differ in adolescents with parents of educational level above primary level, those with adequate awareness and higher annual family income $(\mathrm{P}<0.05)$. Adolescents with frontline worker in family were less likely to have positive behavior though not statistically significant. $(\mathrm{P}=0.44)$. (Table 2$)$
Table 2. Socio-demographic factors associated with positive behavior.

\begin{tabular}{|c|c|c|c|c|}
\hline \multicolumn{2}{|c|}{ Characteristics } & \multirow{2}{*}{$\begin{array}{c}\begin{array}{c}\text { Number } \\
\text { (Percentage) }\end{array} \\
186(62.2)\end{array}$} & \multirow{2}{*}{$\begin{array}{c}\begin{array}{c}\text { Positive } \\
\text { behavior } \\
\text { (\%) }\end{array} \\
80.6\end{array}$} & \multirow{3}{*}{$\begin{array}{l}\text { P value } \dagger \\
<0.001^{*}\end{array}$} \\
\hline \multirow{2}{*}{ Ethnicity } & Brahmin and Chhetri & & & \\
\hline & Others & $113(37.8)$ & 60.2 & \\
\hline \multirow{2}{*}{ Family Type } & Nuclear & $216(72.2)$ & 77.3 & \multirow{2}{*}{$0.009^{*}$} \\
\hline & Extended & $83(27.8)$ & 61.4 & \\
\hline \multirow{2}{*}{$\begin{array}{l}\text { Stream of } \\
\text { Education }\end{array}$} & Non-Technical & $135(60.8)$ & 53.8 & \multirow{2}{*}{$<0.001^{*}$} \\
\hline & Technical & $87(39.2)$ & 82.2 & \\
\hline \multirow{2}{*}{$\begin{array}{l}\text { Mother's } \\
\text { Education } \\
\text { Level }\end{array}$} & Up to Primary & $104(34.8)$ & 62.5 & \multirow{2}{*}{$0.005^{*}$} \\
\hline & Secondary and above & $195(65.2)$ & 78.5 & \\
\hline \multirow{2}{*}{$\begin{array}{l}\text { Father's } \\
\text { Education } \\
\text { Level }\end{array}$} & Up to Primary & $52(17.4)$ & 63.5 & \multirow{2}{*}{0.13} \\
\hline & Secondary and above & 247 (82.6) & 74.9 & \\
\hline \multirow{2}{*}{$\begin{array}{l}\text { Father's } \\
\text { Occupation }\end{array}$} & Non-service & $117(39.1)$ & 65.9 & \multirow{2}{*}{$0.001^{*}$} \\
\hline & Service & $182(61.1)$ & 83.8 & \\
\hline \multirow{2}{*}{$\begin{array}{l}\text { Annual } \\
\text { Income }\end{array}$} & Less than 85,000 & $114(38.1)$ & 61.4 & \multirow{2}{*}{$0.001^{*}$} \\
\hline & More than 85,000 & 185 (61.9) & 80.0 & \\
\hline \multirow{2}{*}{$\begin{array}{l}\text { Awareness } \\
\text { Level }\end{array}$} & Inadequate & $22(7.3)$ & 45.5 & \multirow{2}{*}{$0.006^{*}$} \\
\hline & Adequate & 277 (92.7) & 75.1 & \\
\hline
\end{tabular}

$*$ P value significant $\leq 0.05+$ Chisquare continuity correction

Binary logistic regression was performed to ascertain the effects of significant socio-demographic factors and awareness on behavior. Adolescents with adequate awareness on COVID-19 were 10.67 times more likely to perform positive health related behavior $(\mathrm{P}=0.005 ; 95 \%$ $\mathrm{CI}=2.018-56.47$ ) than those with inadequate awareness. The regression analysis also showed that adolescents of nuclear family (vs. joint/extended) and with higher annual family income (vs. lower income) were significantly associated with positive behaviour. (Table 3)

Table 3. Binary logistic regression on factors associated with positive behavior.

\begin{tabular}{|c|c|c|c|c|}
\hline Variable & Coefficient & $\begin{array}{l}\text { Standard } \\
\text { error }\end{array}$ & $\mathbf{T}$ & $P$ value \\
\hline $\begin{array}{l}\text { Awareness (adequate vs. } \\
\text { inadequate) }\end{array}$ & 2.368 & 0.850 & 10.675 & $0.005^{*}$ \\
\hline $\begin{array}{l}\text { Ethnicity (Brahmin Chhetri vs. } \\
\text { Others) }\end{array}$ & 0.482 & 0.362 & 1.620 & 0.183 \\
\hline Family type (nuclear vs. extended) & 0.990 & 0.383 & 2.692 & $0.010^{*}$ \\
\hline $\begin{array}{l}\text { Stream (technical vs. non- } \\
\text { technical) }\end{array}$ & 0.675 & 0.361 & 1.965 & 0.061 \\
\hline $\begin{array}{l}\text { Mother's educational level } \\
\text { (secondary or higher vs. up to } \\
\text { primary) }\end{array}$ & 0.326 & 0.371 & 1.386 & 0.380 \\
\hline $\begin{array}{l}\text { Father's occupation (service vs. } \\
\text { others) }\end{array}$ & 0.607 & 0.383 & 1.835 & 0.113 \\
\hline $\begin{array}{l}\text { Annual family income (more than } \\
85000 \text { vs. less than } 85000 \text { ) }\end{array}$ & 0.991 & 0.366 & 2.693 & $0.007^{*}$ \\
\hline
\end{tabular}

${ }^{*} \mathrm{P}$ value significant $\leq 0.05$

\section{DISCUSSION}

This study showed that above $90 \%$ of adolescents had adequate awareness on COVID-19. This finding is similar 
to the study done among Chinese residents which showed that $90 \%$ of Chinese residents were aware about COVID-19 and also consistent with a study done in Indonesian community. ${ }^{5,10}$ As the study was done in June when Nepal had gone into seven weeks of lockdown, ${ }^{11}$ adolescents had ample time to gain knowledge about COVID-19 via different sources and online platforms. This is also supported by the fact that $94.6 \%$ of adolescents used internet as the most common source of information regarding COVID-19 and used online news and World Health Organization applications reliable for information. This finding is consistent with the study done in Anhui province of China. ${ }^{12}$ It is evident that the tendency to use internet and online information has been the most accessible source to information in the era of COVID-19 in Nepal also.

Awareness on COVID-19 was found to be adequate among the adolescents who had technical stream of education. Adolescents whose fathers and mothers had educational level "secondary or above" were more likely to have adequate awareness. This finding is similar to a study done among Norwegian adolescents. ${ }^{13}$ This shows that educational level of parents can have significant effect on awareness of their children also. Adolescents with higher family income were found to have adequate awareness. This is consistent with the study done in Malaysia. ${ }^{14}$ This may be likely due to accessible sources of reliable information at home.

In terms of behavior, majority (72\%) of the youth had positive behavior practices. Positive psychological healthrelated behaviors were found in $86 \%$ of adolescents which may be reflective of adolescent's compliance with their awareness from various source of information through internet. Around $84 \%$ of the adolescents had demonstrated positive health-related behaviors in social domain which comprised of the behaviors like maintaining social distance of at least 1 meter, avoiding crowds and use of mask. This finding is similar to the study done in Malaysia which showed that $83.4 \%$ of people kept themselves away from the crowd. ${ }^{14}$

Almost $70 \%$ of adolescents had positive health related behaviors in physical domain manifesting behaviors like hand washing, use of sanitizer, staying home and following respiratory etiquettes, disinfecting phones and devices. This is lower than the study done in China and Indonesia which showed that $88 \%$ and $93 \%$ respectively had disinfecting behaviors. ${ }^{5,10}$ It seems that physical health- related behaviors performed by adolescents in Nepal are decreasing than that from people of China and Indonesia. It may be because of less perceived fear of Nepalese adolescents leading to regressive behaviors due to longer experience of nation-wide lockdown and preventive measures. Nepal had gone into Nation-wide lockdown from the month of March with all the precautions and measures and the data was collected in mid of June. ${ }^{11}$

This study showed that the positive health-related behaviors of adolescents was evident among adolescents who had technical stream of education which may be reflective of possession of good knowledge on disease and human biology among adolescents enrolled in science stream, nursing and engineering. Positive behaviors are imminent among adolescents with nuclear family, mother with educational status secondary level and above, father who had service as an occupation which may be because of the care, concerns and precautions taken by parents in rearing their child.

Adolescents having family annual income more than NRs. 85,000 were significantly found to have positive healthrelated behaviors. Negative health-related behaviors can be reflected from family with low income due to lack of ability to afford and access to health services despite of their awareness on preventive measures. Most importantly awareness level of the adolescent had a positive influence on behavior as seen in adolescents and other age groups and across other countries also. ${ }^{13-15}$

The major limitation of this study is that the findings of this study may not be generalized to entire adolescent's population of Nepal due to online survey and use of nonprobability network sampling. It would have been more effective if the availability of standard questionnaire was there to assess the awareness and health-related behavior of adolescents.

\section{CONCLUSION}

The level of awareness on COVID-19 among adolescents was found adequate. Adolescents with adequate knowledge were more inclined to have positive healthrelated behavior. However, the positive behaviour was not up to the level of awareness, hence it is necessary to provide timely and positive reinforcement to adopt positive health behavior with use of various information, education, and communication measures to the adolescents by the stake holders and policy makers of public health.

Conflicts of interest: None declared 


\section{REFERENCES}

1. World Health Organization WHO. WHO Timeline - COVID-19. Newsroom. 2020. Available from: https://www.who.int/ news-room/detail/27-04-2020-who-timeline---covid-19. [Accessed 10th April, 2020]

2. Jiao WY, Wang LN, Liu J, Fang SF, Jiao FY, Pettoello-Mantovani $\mathrm{M}$, et al. Behavioral and Emotional Disorders in Children during the COVID-19 Epidemic. J Pediatr. 2020;221:264-6 e1. DOI: 10.1016/j.jpeds.2020.03.013 PMID: 32248989.

3. Smetana JG, Campione-Barr N, Metzger A. Adolescent Development in Interpersonal and Societal Contexts. Annual Review of Psychology. 2006;57(1):255-84. DOI: 10.1146/ annurev.psych.57.102904.190124 PMID: 16318596.

4. Ajilore K, Atakiti I, Onyenankeya K. College students' knowledge, attitudes and adherence to public service announcements on Ebola in Nigeria: Suggestions for improving future Ebola prevention education programmes. Health Education Journal. 2017;76(6):648-60. DOI: 10.1177/0017896917710969

5. Zhong B-L, Luo W, Li H-M, Zhang Q-Q Liu X-G, Li W-T, et al. Knowledge, attitudes, and practices towards COVID-19 among Chinese residents during the rapid rise period of the COVID-19 outbreak: a quick online cross-sectional survey. Int J Biol Sci. 2020;16(10):1745-52. DOI: 10.7150/ ijbs.45221 PMID: 32226294.

6. McIntosh K, Hirsch MS, Bloom A. Coronavirus disease 2019 (COVID-19). UpToDate Hirsch MS Bloom. 2020 Mar;5:11. Available from: Coronavirus_disease2019_COVID-19 UpToDate2.pdf (cmim.org). [Accessed $3^{\text {rd }}$ September, 2020]

7. Taber KS. The Use of Cronbach's Alpha When Developing and Reporting Research Instruments in Science Education. Research in Science Education. 2018;48(6):1273-96. DOI: 10.1007/s11165-016-9602-2

8. Cochran WG. Relative accuracy of systematic and stratified random samples for a certain class of populations. The Annals of Mathematical Statistics. 1946:164-77. DOI: 10.1016/j.ijantimicag.2020.105955
9. Lwanga SK, Lemeshow S, Organization WH. Sample size determination in health studies: a practical manual: World Health Organization; 1991. Available from: https://apps.who.int/iris/bitstream/ handle/10665/40062/9241544058\%28p1-p22\%29.pdf [Accessed 10th April, 2020]

10. Yanti B, Wahyudi E, Wahiduddin W, Novika RGH, Arina YMDa, Martani NS, et al. Community Knowledge, Attitudes, and Behavior Towards Social Distancing Policy As Prevention Transmission of Covid-19 in Indonesia. Jurnal Administrasi Kesehatan Indonesia. 2020;8(2):4-14. DOI: 10.20473/jaki. v8i2.2020.4-14

11. Ministry of Health and Population, Government of Nepal. Coronavirus disease (COVID-19) outbreak updates and resource materials. Situation report 42. . Available from: https://heoc.mohp.gov.np/update-on-novel-corona-viruscovid-19. [Accessed 3rd September, 2020]

12. Chen Y, Jin YL, Zhu LJ, Fang ZM, Wu N, Du MX, et al. [The network investigation on knowledge, attitude and practice about COVID-19 of the residents in Anhui Province]. Zhonghua Yu Fang Yi Xue Za Zhi. 2020;54(4):367-73. DOI: $10.3760 / c m a . j . c n 112150-20200205-00069$ PMID: 32268643.

13. Riiser K, Helseth S, Haraldstad K, Torbjørnsen A, Richardsen KR. Adolescents' health literacy, health protective measures, and health-related quality of life during the Covid-19 pandemic. PLOS ONE. 2020;15(8):e0238161. DOI: 10.1371/ journal.pone.0238161

14. Azlan AA, Hamzah MR, Sern TJ, Ayub SH, Mohamad E. Public knowledge, attitudes and practices towards COVID-19: A cross-sectional study in Malaysia. PLOS ONE. 2020;15(5):e0233668. DOI: 10.1371/journal. pone.0233668

15. Dirawan GD, Yahya M, Taiyeb M. The Community Disease Prevention Behaviors in District Maros South Sulawesi Province. International Education Studies. 2015;8(11):104. DOI: $10.5539 /$ ies.v8n11p104 